\title{
Hepatic Dysfunction with Systemic Antifungal Agents
}

\author{
Nasir Khokhar, M.D.
}

DOI: http://dx.doi.org/10.5915/18-3_4-12803

Successful therapy of many systemic fungal infections has been possible with the availability of several antifungal agents (Table I). However, most of these drugs may have potential hepatotoxic side effects since they are partly metabolized and degraded through the liver. Hepatic dysfunction is generally not a very serious problem, but caution is required so that adequate monitoring may be done to avoid more severe complications. This paper will summarize the hepatic reactions from the antifungal agents with particular reference to a recently used drug, ketoconazole.

\section{TABLE I}

\section{SYSTEMICALLY USED ANTIFUNGAL DRUGS}

1. Nystatin

2. Criseofulvin

3. 2-hydroxystilbamidine

4. 5-fluorocytosine

5. Amphotericin B

6. Imidazoles

a. Miconazole

b. Ketoconazole

\section{ANTIFUNGAL DRUGS}

\section{5-Fluorocytosine:}

Elevation of transaminases and alkaline phosphatase with enlarged and tender liver was found in 2 out of 17 patients treated with $70-90 \mathrm{mg} / \mathrm{kg} /$ day dosage (1). One patient has prior treatment with Amphotericin B. Serum glutamic oxaloacetic transaminase (SGOT, serum aspartate aminotransferase) and serum glutamic pyruvic transaminase (SGPT, serum alanine aminotransferase) were increased 3-5 times the normal, but returned to baseline after decreasing the dose in one patient, and after 7 days of stopping the drug in the other (1). Hepatic effects were considered reversible and dose related.

\section{Amphotericin B:}

"Acute toxic degeneration" was the name given to

Nasir Khokhar, M.D.

Chairman, Department of Medicine

Pekin Memorial Hospital

Pekin, IL 61554

Address reprint requests to:

350 St. Mary St.

Pekin, IL 61554 autopsy findings of the liver of a 32 year old patient who was treated with $4.82 \mathrm{G}$ of the drug in 4 separate courses in one years time for cryptococcal meningoencephalitis (2). The liver showed marked lobular fatty infiltration. Such reactions are rare and relation with amphotericin B is questionable (3).

\section{Griseofulvin, 2-Hyroxystilbamidine, and Nystatin:}

Earlier animal reports suggested hepatotoxicity with Griseofulvin (4), but long and extensive usage has not shown any significant liver damage in humans.

2-Hydroxystilbamidine is used in North American Blastomycosis and SGOT elevation of 2 or more times was noted in 21 of 43 patients, and serum bilirubin was elevated in 3 patients (5). The drug was given as $225 \mathrm{mg}$ /day for 6 days of a week until $8 \mathrm{G}$ was given. In another study "Hepatitis" was noted to have occurred in 2 of 66 patients treated with 2-hydroxystilbamidine (6).

Since most of Nystatin is unabsorbed from the gastrointestinal tract, no hepatic reactions have been noted.

\section{Imidazoles:}

Imidazoles are a group of drugs which are related to anti-thyroid drugs carbimazole and methimazole and anti-protozoal metronidazole. Miconazole has not shown hepatic dysfunction so far. Ketoconazole has been used in a wide variety of mycotic infections. Liver function abnormalities have occurred after ketoconazole (7-11), but direct causal relationship has been difficult to establish. Since several patients had abnormal liver enzymes (see below) even before treatment with ketoconazole, it has been thought that hepatotoxic mycotxins may have some role, as several fungi can produce such substances (12). Also annual incidence of hepatitis in the general population is around 28 per 100,000 (13), and a study of biopsy material from patients who developed hepatic dysfunction after ketoconazole has shown hepatitis indistinguishable from other drug hepatitidis (8-9). Hepatic reactions from ketoconazole have been classified as silent and symptomatic.

SILENT REACTIONS. A $50 \%$ increase in SGOT. SGPT, alkaline phosphatase, or gammaglutamyl transpeptidase (GGTP) without any symptoms is considered a silent reaction. In a study of 1074 patients treated with ketoconazole, this was found in $14 \%$ of patients; however, $8 \%$ can occur at any time after ketoconazole therapy. This has been regarded 
harmless and discontinuation of the drug is not required. Generally, the liver enzymes have returned back to normal after stopping ketoconazole, and even may return to normal in spite of continued administration of the drug.

SYMPTOMATIC REACTIONS. They can be icteric or non-icteric (Table II). The estimated incidence is 1 in 12,000 . Time of onset, on an average, is 6-11 weeks after starting the drug. It is not possible to predict who will develope a symptomatic reaction after ketoconazole, but there are certain categories of patients who have had such effects (Table III). Symptoms tend to subside after the drug is withdrawn, although fatalities have been recorded (11). A symptomatic reaction due to ketoconazole is described here.

\section{TABLE II}

\section{SYMPTOMATIC REACTIONS}

1. Icteric

Jaundice

Dark Urine

Pale Stools

2. Anicteric

Fever

Fatigue, Weakness, Malaise

Anorexia, Nausea, Vomiting

TABLE III

\section{CONDITIONS ASSOCIATED WITH} SYMPTOMATIC REACTIONS

1. Age above 50

2. Female sex

3. Previous history of hepatitis

4. Previous history of drug idiosyncracy

5. Previous history of griseofulvin therapy

6. Onychomycosis

CASE REPORT. A 72 year old female has swelling, redness, and pain around the nail of her right index finger for 10 months. This was thought to be due to candidial infection. She had been on naproxen $250 \mathrm{mg}$ BID for arthritis and thorazine $75 \mathrm{mg}$. HS for three years. Oral griseofulvin for 6 months was ineffective, and she was started on $200 \mathrm{mg} /$ day ketoconazole. Liver profile was normal. Eight weeks later, she developed nausea, anorexia, nervousness, palpitation and abdominal discomfort. Physical examination showed no jaundice, and the liver was not palpable. Laboratory data revealed serum aspartate aminotransferase (SGOT) of 48 (N-4-30). Ketoconazole was discontinued. Hepatitis B surface antigen and antibody were absent. Three weeks later, all the abnormal tests returned to normal. Symptoms of nausea, anorexia, perspiration, all resolved during this time.

\section{MECHANISM}

Not much is known about the mechanisms of hepatic dysfunction by these drugs. However, since most of the effects consist of enzymes elevation, it seems that some of these agents cause hepatocellular injury.

\section{MANAGEMENT}

No specific measures are generally required in case of amphotericin B in regard to hepatic toxicity. If a patient is on griseofulvin for prolonged period of time, occasional liver profile studies are advised (4).

Patients on ketoconazole should have a baseline SMA-12 (or liver profile) and should have recheck SMA-12 every month during the period of therapy or frequently if necessary. If any significant liver abnormalities are detected, it is best to discontinue the drug, if at all possible, since fatal outcome has occurred.

\section{SUMMARY}

Antifungal agents that are used systemically have the potential of hepatotoxicity. Among clinically used drugs, ketoconazole has caused hepatic reactions with enzyme elevation and these can be symptomatic. Baseline and periodic monitoring of liver functions is advised and implicated agent should preferably be discontinued on any significant liver function abnormality.

\section{References}

1. Steer PL, Marks MI, Klite PD, Eickhoff TC: 5-Fluorocytosine. An oral antifungal compound. A report on clinical and laboratory experience. Ann. Int. Med. 76:15-22, 1972.

2. Carnecchia BM, Kurtzke JF: Fatal Toxic reaction to amphotericin B in cryptococcal meningo-encephalistis. Ann. Int. Med. 53:1027-1036, 1960.

3. Bennett JE: Chemotherapy of systemic mycosis. New Eng. J. Med. 290:30-32, 1974.

4. Goldman L: Griseofulvin. Med. Clin. N. Am. 54:1339-1345, 1970

5. Busey JF: 'Blastomycosis. III. A comparative study of 2-hydroxystilbamidine and amphotericin B therapy. Am. Rev. Resp. Dis. 105:812-818, 1972.

6. Blastomycosis. I. A review of 198 collected cases in Veteran Administration hospitals. Blastomycosis cooperative study of the Veretans Administration. Am, Rev. Resp. Dis. $89: 659-672,1964$.

7. Dismukes WE, Stamm AM, Graybill JR, et al: Treatment of Systemic Mycosis with Ketoconazole: Emphasis on toxicity and clinical response in 52 patients. National Institute of Allergy and Infectious Diseases collaborative antifungal study. Ann. Int. Med. 98:13-20, 1983.

8. Petersen EA, Alling DW, Kirkpatrick $\mathrm{CH}$ : Treatment of chronic mucocutaneous candidiasis with ketoconazole: A controlled clinical trial. Ann. Int. Med. 93:791-795, 1980. 
9. Heiberg JK, Svejgaard E: Toxic hepatitis druging ketoconazole treatment. Br. Med. Jour. 283:825, 1981.

10. MacNair AL, Gascoigne E, Heap J, et al: Hepatitis and ketoconazole therapy. Br. Med. Jour. 283:1058-1059, 1981.

11. Janssen PAJ, Symoens JE: Hepatic reactions during ketoconazole treatment. Am. Jour. Med. (Supp) 80-85, 1983.
12. Carlton WW, Stack ME, Eppley RM: Hepatic alterations produced in mice by xanthomegnin and viomellein, metabolics of penicilliium viridacatum. Toxical Appl. Pharmacol. 38:455-459, 1976.

13. Koff RS, Galmbos J: Viral hepatitis, in diseases of Liver, 5th Ed. (Editors: Schiff L and Schiff ER), JB Lippincott Co., Philadelphia, 1982, p. 489. 